\title{
New mouse models of autism highlight need for standardized tests
}

Most laboratory mice, when meeting new cagemates, will sniff the strangers thoroughly. But the mice in Matthew Anderson's lab instead sit alone, licking their paws repetitively. They ignore other mice, avoid new toys and rarely make noise. Taken together, the abnormalities closely resemble the behavioral symptoms seen in people with autism, a disorder that has been proven difficult to accurately recapitulate in animal models-until recently.

"When I first started working on this, I really wondered whether we'd be able to study autism in a mouse," says Anderson, a neuroscientist at the Beth Israel Deaconess Medical Center in Boston. "But these mice act just like you would expect with autism. I was pleasantly surprised."

Mouse models for autism first started to emerge around ten years ago. And as researchers have discovered more genes linked to the disease, they have continued to generate more mouse models that are collectively providing the field with a window into the brain structure, neuron function and cellular pathways associated with autism, as well as a platform for testing new drugs. But as more models emerge, it has become increasingly clear that the field needs standardized behavioral assays to compare the effects of the different genetic mutations more clearly. "All these mice have been tested in different labs using different paradigms," says Daniel Geschwind, a neurogeneticist at the University of California-Los Angeles. "People bandy about repetitive behavior, for example, but what some folks call repetitive behavior is different than what others call repetitive behavior."

One of the newest models was published earlier this year by molecular geneticist Guoping Feng, of the Massachusetts Institute of Technology's McGovern Institute for Brain Research in Cambridge. In March, Feng and his colleagues showed that deleting a gene called Shank3, which encodes a protein that helps stabilize synapses between neurons, in mice produced the same three core symptoms of autism as seen in people: abnormal social interactions, communication deficits and repetitive behavior ${ }^{1}$. The same month, a team led by Paul Worley of Johns Hopkins University in Baltimore published a mouse model in which they deleted only one exon of the Shank3 gene, a bit known to code for an active binding site, and found similar social problems in a series of behavioral assays ${ }^{2}$.

More recently, Geschwind reported a mouse model in late September with a mutation in

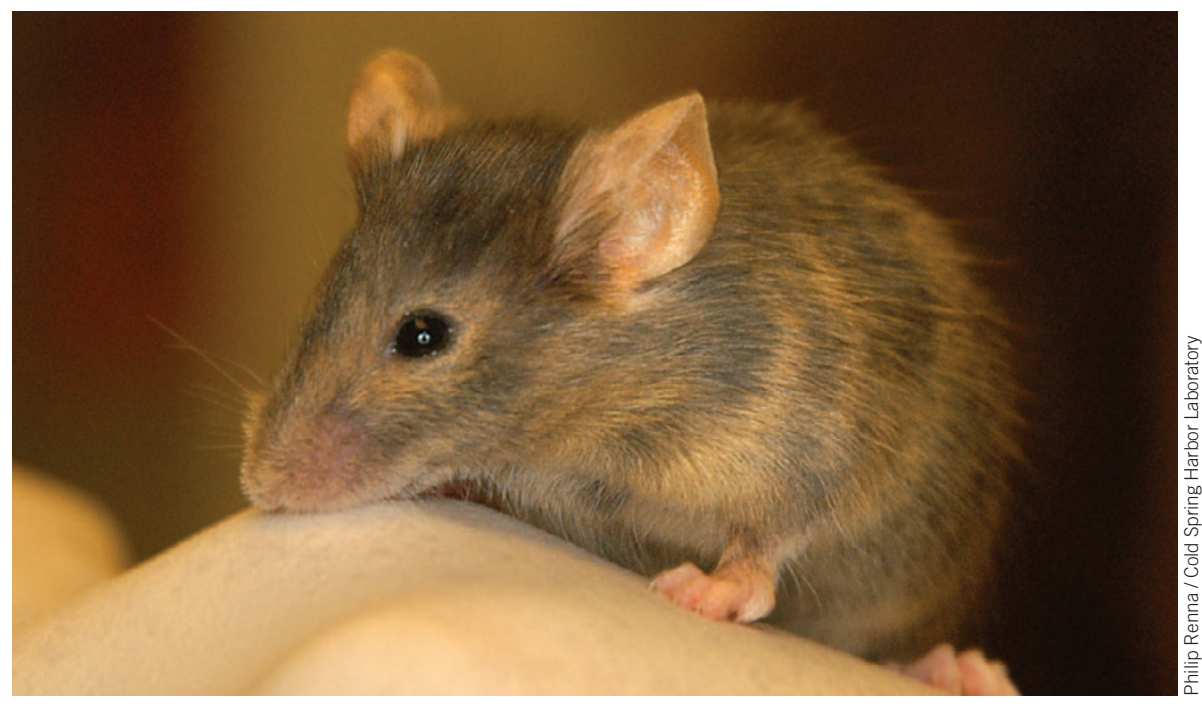

Repeat performance: Mouse models such as Alea Mills's (pictured) show behavioral deficits.

CNTNAP2, a gene linked to both a familial epilepsy disorder and autism ${ }^{3}$. And, last month, Anderson and his collaborators described mice with duplications in Ube3a, a gene involved in protein degradation that has also been linked to human autism ${ }^{4}$. His mice, Anderson says, don't avoid other mice, as has been seen in some models, but simply ignore them. It's a subtle difference, but one that suggests his mice show signs of autism, not social anxiety. Not all models have made this distinction, he says, and it highlights the difficulty in comparing each piece of research.

\section{A quick study}

At the US National Institute of Mental Health (NIMH) in Bethesda, Maryland, Jacqueline Crawley is working to develop a standardized set of tests to help sort out such subtleties. Among other things, she's studying the normal course of mice vocalizations to help researchers better identify irregular communication patterns. New, highly sensitive microphones have allowed her team to track the sounds mice make in the ultrasonic range, which humans can't hear.

"The ultimate goal is to have a small set of quick assays," says Crawley, head of the NIMH's behavioral neuroscience laboratory. But researchers also have to learn how to perform the assays correctly, she adds. Many of the labs testing mouse models have expertise in neurogenetics, not behavior. As a result, "they're making a lot of rookie mistakes," Crawley says, "and it's unfortunately leading to a lot of findings which aren't true or won't be able to be replicated."
Until the field has agreed on standards, one approach is to observe mice more broadly. Last month, for instance, a team led by Alea Mills of the Cold Spring Harbor Laboratory in Long Island, New York debuted a mouse strain in which they altered the copy number of a large stretch of chromosome 16 previously implicated in autism in people. Rather than challenging the mice with set assays, Mills's group equipped the mouse cages with video tracking systems and followed each mouse's every move for weeks at a time. Mice with genetic duplications, they found, were more timid about exploring new, larger cages than their healthy counterparts ${ }^{5}$.

"You see what you look for," says Mills. "We really felt like we should look at everything rather than start out with assumptions about what the mice should or shouldn't be able to do."

The ultimate purpose of mouse models, of course, is to provide testing grounds for drugs and to shed light on the molecular underpinnings of autism in the brain. And, as Anderson points out, more mice to work with-however different they are-means more evidence for the field. "The more models we have of actual human autism in mice," he says, "the more convergence of pathways we hope we will find."

Sarah C P Williams

1. Peça, J. et al. Nature 472, 437-442 (2011)

2. Bangash, M.A. et al. Cell 145, 758-772 (2011).

3. Peñagarikano, O. et al. Cell 147, 235-246 (2011).

4. Smith, S.E.P. et al. Sci. Trans. Med. 103, 103 ra97 (2011).

5. Horev, G. et al. Proc. Natl. Acad. Sci. USA 108 17076-17081 (2011) 